Frantisek Ábel

\title{
The Psalms of Solomon and the Messianic Ethics of Paul
}

[Die Psalmen Salomos und die messianische Ethik des Paulus.]

FRANTIŠEK ÁBEL

The Psalms of Solomon and the Messianic Ethics

of Paul

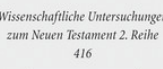

Mohr Siebeck

2016. XV, 355 Seiten. WUNT II 416

ISBN 978-3-16-153992-3

DOI 10.1628/978-3-16-153992-3

eBook PDF $104,00 €$

ISBN 978-3-16-153991-6

fadengeheftete Broschur 104,00€
Veröffentlicht auf Englisch.

František Ábel untersucht die Rolle und den Einfluss jüdischer Pseudepigraphen - Literatur, die während der griechischen und frühen römischen Zeit (zwischen dem 4 Jhd. v. Chr und 2 Jhd. n. Chr) entstanden ist - bezüglich der theologischen Ansichten des Paulus. Eschatologische Vorstellungen, wie die Ankunft des Messias und das Jüngste Gericht, tauchen in diesem Textkorpus häufig auf. Ähnlich ist es im Fall der Psalmen Salomos, einem Pseudepigraphon, welches das Jüngste Gericht thematisiert. Der Autor zeigt durch eine detaillierte Analyse und Untersuchung bestimmter Teile dieses Textes, dass diese deuterokanonische Schrift einen beachtlichen Hintergrund für das Verständnis der Gestaltung und Entwicklung der messianischen Ethik des Paulus bieten kann. Aus diesem Blickwinkel sollte die Rechtfertigungslehre des Paulus als Widerspiegelung der Gnade Gottes verstanden werden, während gleichzeitig Glaube und Werke als für die Erlösung ausgewiesen werden.

Frantisek Ábel Born 1964; 2006 PhD; 2006-12 assistant professor at the New Testament Department of the Evangelical Lutheran Theological Faculty of Comenius University in Bratislava; 2007-11 assistant dean of academic affairs, since 2013 associate professor.
Jetzt bestellen:

https://mohrsiebeck.com/buch/the-psalms-of-solomon-and-the-messianic-ethics-of-paul-9783161539923?no_cache=1 order@mohrsiebeck.com

Telefon: +49 (0)7071-923-17

Telefax: +49 (0)7071-51104 